\title{
Experimental study on vibration characteristics of metro tunnels with different track structures
}

\author{
Baoyou Wu ${ }^{1}$, Tianyu Liu ${ }^{2}$, Yongfei $\mathrm{Ai}^{3}$, Qingjie Liu ${ }^{4}$, Lizhong Song \\ ${ }^{1,3}$ China Railway Electrification Bureau Group Co., Ltd., Beijing 100036, China \\ 2, 4, ${ }^{\mathrm{MOE}}$ Engineering Research Centre of Railway Environmental Vibration and Noise, East China \\ Jiaotong University, Nanchang 330013, China \\ ${ }^{5}$ Corresponding author

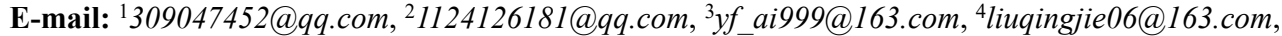 \\ ${ }^{5}$ songlizhong@ecjtu.edu.cn
}

Received 12 April 2021; received in revised form 23 April 2021; accepted 30 April 2021 DOI https://doi.org/10.21595/vp.2021.21991

Check for updates

Copyright $(2021$ Baoyou Wu, et al. This is an open access article distributed under the Creative Commons Attribution License, which permits unrestricted use, distribution, and reproduction in any medium, provided the original work is properly cited.

\begin{abstract}
To explore the vibration transmission characteristics and vibration reduction effects of metro tunnels with different track structures, the regular slab track section, the double-layer nonlinear vibration-damping fastener section and the isolated damping pad section in the Nanchang Metro Line 3 were selected respectively for the field hammer excitation test. Based on the field test results, the vibration transmission characteristics and the vibration reduction effects of metro tunnels with different track structures were analyzed. The results indicated that the vibration reduction effect of the isolated damping pads was best, followed by the double-layer nonlinear vibration-damping fasteners, while that of the regular slab tracks was worst; the double-layer nonlinear vibration-damping fastener section had obvious vibration reduction effect in the frequency range of 80 to $170 \mathrm{~Hz}$, the isolated damping pad section had significant vibration reduction performance above $30 \mathrm{~Hz}$; the vibration of the double-layer nonlinear vibration-damping fastener section and the isolated damping pad section was $5.6 \mathrm{~dB}$ and $10 \mathrm{~dB}$ less than the regular slab track section, respectively.
\end{abstract}

Keywords: vibration characteristics, vibration reduction effect, track structure, hammer excitation test, metro tunnel.

\section{Introduction}

The fast development of the urban railway system in China in recent years has greatly met the travel needs of the public. The urban railway system also plays an increasingly significant role in optimizing the urban structural layout, alleviating urban traffic congestion, and promoting the economic and social development. Statistically, a total of 45 cities in the mainland of China have built urban railway system by December 31,2020 . In the $7,978.19 \mathrm{~km}$ lines in operation, metro lines were $6,302.79 \mathrm{~km}$, accounting for $79 \%$ [1].

The large-scale construction of metro lines makes the vibration and noise problems increasingly prominent. When a train runs on the rails, the interaction between the wheel and the rails due to the uneven rails leads to the wheel-rail force and induces the wheel-rail system to vibrate. The vibration is transmitted to the tunnel wall through the track structure, and then to the ground, resulting in the vibration of ground buildings and secondary structural noise [2].

Scholars have carried out a great number of studies on the vibration problem caused by metro [3] and vibration test methods [4]. In terms of the vibration transmission characteristics of metro tunnels, Yuan et al. [5] studied the vibration transmission characteristics of the tunnel-stratumbuilding system under different vibration sources through laboratory hammer excitation tests and numerical simulations, and found that the transmissibility function of the tunnel-stratum-building system was the intrinsic property of the system, and was unrelated to the vibration amplitude, spectral characteristics and other factors. Hou et al. [6] compared the vibration transmission characteristics of the short rail section (Type III vibration fastener + track bed with short sleeper) and long rail section (regular fastener + track bed with long sleeper) in the tunnel of Suzhou Rail 
Transit Line 1 by hammer excitation test, the test results indicated that Type III vibration fastener + track bed with short sleeper had better vibration reduction effect, and the vibration peak attenuation in the frequency band from 40 to $80 \mathrm{~Hz}$ was about $10 \mathrm{~dB}$. He [7] conducted hammer excitation tests on the south extended section of the Shenzhen Metro Line 5 to investigate the vibration transmission characteristics of different materials including asphalt, rubber, and foam concrete. According to the test results, among the tested materials, asphalt material had the largest vibration peak attenuation while the foam concrete had the least. Cai et al. [8] carried out a field test on the Beijing Metro Line 15 to investigate the vibration reduction effect when the train passed the elastic long sleeper track. Compared with the regular ballastless track, the total vibration acceleration level (VAL) of the elastic long sleeper track was reduced by about $10 \mathrm{~dB}$. Xu et al. [9] found that the rubber mat layer under the track slab can greatly reduce the vibration of the high-speed railway tunnel.

In this paper, hammer excitation tests were performed on the regular slab track section, the double-layer nonlinear vibration-damping fastener section and the isolated damping pad section in the Nanchang Metro Line 3 to investigate the vibration transmission performance of metro tunnels with different track structures. On this basis, the vibration reduction effects of metro tunnels with different track structures were analyzed.

\section{Test overview}

\subsection{Test background}

The test site was selected at the Nanchang Metro Line 3. Its total length is $28.5 \mathrm{~km}$. This line goes through Shengjin Tower Historical Block, Three Wells Historic Conservation Area, Nanchang New Fourth Army Site, Former Residence of Chen Yun, Meihu Natural and Historic Scenic Area, and other historical buildings. Vibration reduction measure such as double-layer nonlinear vibration-damping fasteners and isolated damping pads should be taken for the vibration-sensitive areas. Hammer excitation test was performed before the line was launched to test the vibration transmission characteristics and vibration reduction effects of metro tunnels with different track structures.

\subsection{Layout of measuring points}

In order to test the vibration transmission characteristics and vibration reduction effects of metro tunnels with different track structures, the regular slab track section, the double-layer nonlinear vibration-damping fastener section and the isolated damping pad section were selected, vibration acceleration sensors were pasted on the rail top, the centre of the track slab and the tunnel wall. As shown in Fig. 1, the measuring point (1) was on the top of the rail directly above the fastener, the measuring point (2) was on the top of the rail between two adjacent fasteners, and the measuring point (3) was at the center of the track slab, the measuring point (4) was $1.5 \mathrm{~m}$ high on the tunnel wall. The measuring points (1), (3), and (4) were located on the same section.

\subsection{Test conditions}

In this test, the regular slab track section, the double-layer nonlinear vibration-damping fastener section and the isolated damping pad section were selected. The excitation point was near the measuring point (1). To ensure the validity of the test results, the hammer excitation test was performed for three times for each section. The test conditions are given in Table 1.

\subsection{Test equipment}

In this test, the Coinv hammer designed by China Orient Institute of Noise \& Vibration was used for hammering, and the PCB333B32 acceleration sensor designed by PCB Piezotronics, Inc. 
adopted to record the vibration acceleration of the rail, and the PCB393B04 acceleration sensor designed by PCB Piezotronics, Inc. utilized to record the vibration acceleration of the track slab and the tunnel wall. The DEMO-SQIII-GZ data acquisition instrument designed HEAD Acoustics $\mathrm{GmbH}$ was used to collect force signal and vibration acceleration signal synchronously.

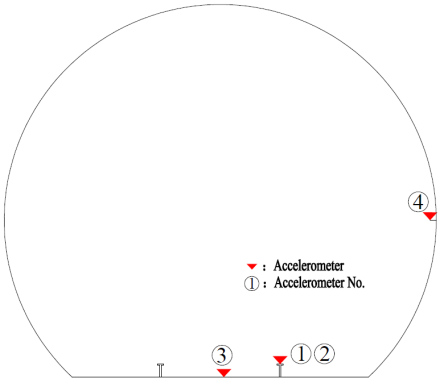

a) Cross-sectional view

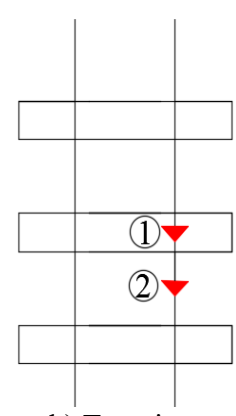

b) Top view

Fig. 1. Schematic diagram of the layout of the measuring points

Table 1. Test conditions

\begin{tabular}{|c|c|}
\hline Test section & Test condition \\
\hline \multirow{2}{*}{ Regular slab track section } & RS-1 \\
\cline { 2 - 2 } & RS-2 \\
\cline { 2 - 2 } Double-layer nonlinear vibration-damping fastener section & RS-3 \\
\cline { 2 - 2 } & DL-1 \\
\cline { 2 - 2 } & DL-2 \\
\hline \multirow{2}{*}{ Isolated damping pad section } & ID-1 \\
\cline { 2 - 2 } & ID-2 \\
\cline { 2 - 2 } & ID-3 \\
\hline
\end{tabular}

\section{Analysis of test results}

According to the time history and frequency spectrum curves of the hammering force for the RS-1 test condition shown in Fig. 2, the time-domain peak value of the hammering force was about $12 \mathrm{kN}$; the frequency spectrum attenuation characteristics of the hammering force was good in the frequency range of 0 to $1000 \mathrm{~Hz}$. The test results therefore can be used to analyze the vibration transmission characteristics of metro tunnels with different track structures.

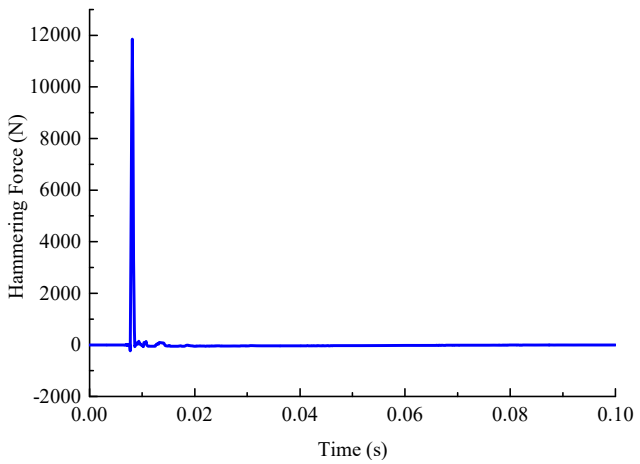

a) Time history

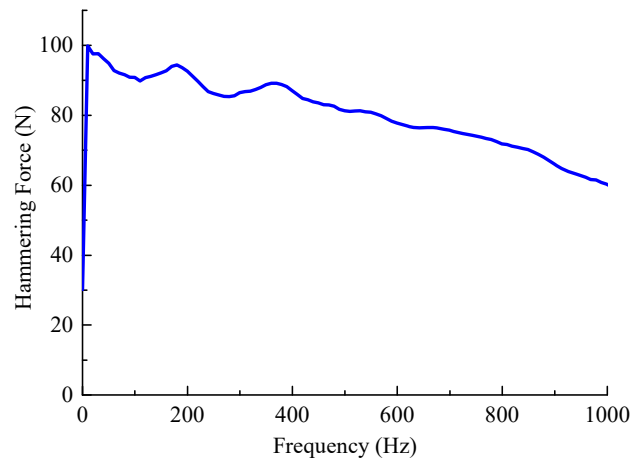

b) Frequency spectrum

Fig. 2. Hammering force 


\subsection{Vibration transmission characteristics}

Vibration acceleration admittance is the ratio of the response signal of the output vibration acceleration to the Fourier transform of the input excitation signal, which reflects the intrinsic vibration characteristics of the structure and is unrelated to the input.

To study the vibration transmission characteristics of metro tunnels with different track structures, the vibration acceleration admittance of each measuring point in the regular slab track section, the double-layer nonlinear vibration-damping fastener section and the isolated damping pad section were calculated.

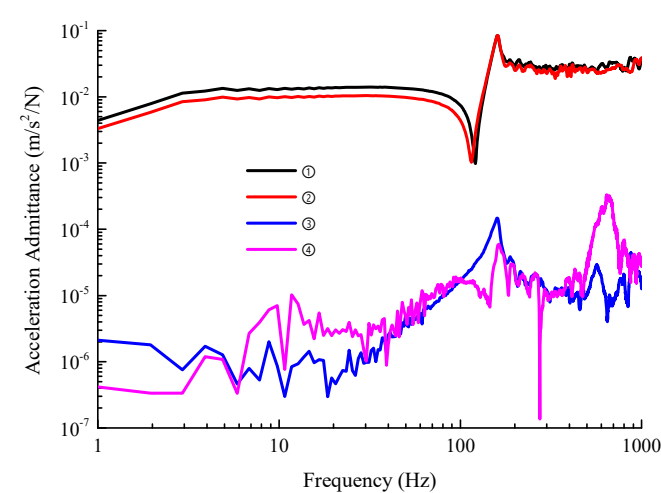

a) RS-1

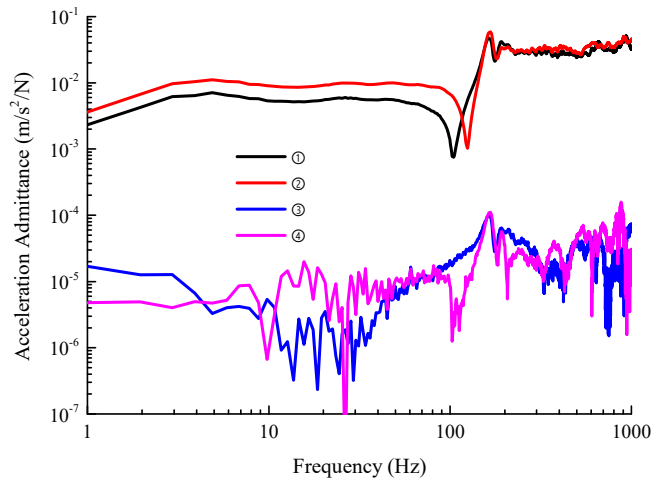

b) DL-1

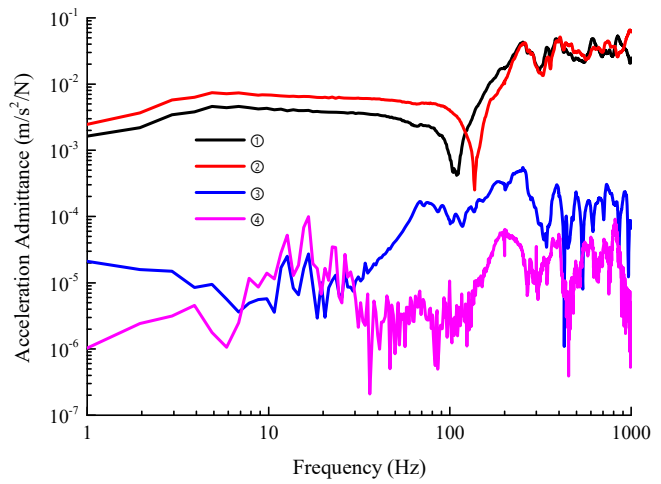

c) ID-1

Fig. 3. Spectra of vibration acceleration admittance of metro tunnels with different track structures

According to the frequency spectrum of vibration acceleration admittance for test conditions of RS-1, DL-1, and ID-1 shown in Fig. 3, there was no big difference in terms of the vibration acceleration admittance of the rail in each test section. The obvious difference of the vibration acceleration admittance of the track slab and the tunnel wall among different test sections suggests that the metro tunnels with different track structures have different vibration transmission characteristics. Regarding the regular slab track section, the vibration acceleration admittance of the tunnel wall was significantly larger than the vibration acceleration admittance of the track slab in the frequency range of 7 to $100 \mathrm{~Hz}$ and 400 to $800 \mathrm{~Hz}$, and it was significantly smaller than the vibration acceleration admittance of the track slab only in the frequency range of 100 to $160 \mathrm{~Hz}$. In terms of the double-layer nonlinear vibration-damping fastener section, the vibration acceleration admittance of the tunnel wall was significantly larger than the vibration acceleration admittance of the track slab only in the frequency range of 10 to $40 \mathrm{~Hz}$, but significantly smaller than the vibration acceleration admittance of the track slab in the frequency range of 80 to $170 \mathrm{~Hz}$. In regard to the isolated damping pad section, the vibration acceleration admittance of the tunnel 
wall was significantly smaller than the vibration acceleration admittance of the track slab above $30 \mathrm{~Hz}$. The test results suggested that the isolated damping pad has the best vibration reduction effect, followed by the double-layer nonlinear vibration-damping fastener while the regular slab track has the poorest vibration reduction effect.

\subsection{Analysis of vibration reduction effect}

To further study the vibration reduction effect of the double-layer nonlinear vibration-damping fastener section and the isolated damping pad section compared to the regular slab track section, the VAL of each measuring point pasted on the regular slab track section, the double-layer nonlinear vibration-damping fastener section and the isolated damping pad section under unit force were calculated, respectively.

The VAL of each measuring point in different test sections under the unit force was given in Table 2. According to Table 2, there was little difference regarding the VAL of the rail in different test sections under the unit force, and the VAL of the same measuring point in same test section for different test conditions were almost same, proving the validity of the test data. It can be also found that under the action of unit force, the VALs of track slab (measuring point (3)) in the regular slab track section, the double-layer nonlinear vibration-damping fastener section and the isolated damping pad section increased in proper order, 58.38, 60.91, $75.87 \mathrm{~dB} / \mathrm{N}$ respectively, while the VALs of tunnel wall (measuring point (4)) decreased in proper order, 69.22, 63.63, $59.19 \mathrm{~dB} / \mathrm{N}$ respectively. Thus, compared to the regular slab track section, the vibration reduction effect of the double-layer nonlinear vibration-damping fastener section and the isolated damping pad section was about 5.6 and $10 \mathrm{~dB}$, respectively.

Table 2. VAL of each measuring point in different test sections under the unit force, Unit: $\mathrm{dB} / \mathrm{N}$

\begin{tabular}{|c|c|c|c|c|c|}
\hline \multirow{2}{*}{ Test section } & $\begin{array}{c}\text { Test } \\
\text { condition }\end{array}$ & $\begin{array}{c}\text { VAL of } \\
\text { measuring } \\
\text { point (1) }\end{array}$ & $\begin{array}{c}\text { VAL of } \\
\text { measuring } \\
\text { point (2) }\end{array}$ & $\begin{array}{c}\text { VAL of } \\
\text { measuring } \\
\text { point (3) }\end{array}$ & $\begin{array}{c}\text { VAL of } \\
\text { measuring } \\
\text { point (4) }\end{array}$ \\
\hline \multirow{2}{*}{$\begin{array}{c}\text { Regular slab track } \\
\text { section }\end{array}$} & RS-1 & 119.44 & 118.64 & 58.34 & 69.34 \\
\cline { 2 - 6 } & RS-2 & 118.56 & 118.72 & 59.24 & 70.21 \\
\cline { 2 - 6 } & RS-3 & 121.07 & 120.50 & 57.55 & 68.10 \\
\hline $\begin{array}{c}\text { Double-layer nonlinear } \\
\text { vibration-damping } \\
\text { fastener section }\end{array}$ & DL-1 & 119.77 & 120.59 & 60.38 & 63.18 \\
\cline { 2 - 6 } & DL-2 & 118.68 & 120.37 & 62.20 & 64.90 \\
\cline { 2 - 6 } $\begin{array}{c}\text { Isolated damping pad } \\
\text { section }\end{array}$ & DL-3 & 119.78 & 121.06 & 60.16 & 62.80 \\
\cline { 2 - 6 } & ID-1 & 119.57 & 120.21 & 75.72 & 59.09 \\
\cline { 2 - 6 } & ID-2 & 118.57 & 119.34 & 74.87 & 58.17 \\
\hline
\end{tabular}

\section{Conclusions}

To explore the vibration transmission characteristics and vibration reduction effect of metro tunnels with different track structures, the regular slab track section, the double-layer nonlinear vibration-damping fastener section and the isolated damping pad section in the Nanchang Metro Line 3 were selected respectively for the field hammer excitation test with the following major conclusions:

1) Among the three types of track structure, the isolated damping pad section has the best vibration reduction effect, followed by the double-layer nonlinear vibration-damping fastener section, while the regular slab track section has the worst vibration reduction effect.

2) In the range of 80 to $170 \mathrm{~Hz}$, the double-layer nonlinear vibration-damping fastener has obvious vibration reduction effect. Compared with the regular slab track, its vibration reduction effect is about $5.6 \mathrm{~dB}$.

3) The isolated damping pad demonstrates significant vibration reduction characteristics above $30 \mathrm{~Hz}$. Compared with the regular slab track section, its vibration reduction effect is about $10 \mathrm{~dB}$. 


\section{Acknowledgements}

The authors are grateful for the financial supports from the National Natural Science Foundation of China (Grant No. 52008169) and Natural Science Foundation of Jiangxi Province (Grant No. 2020BAB204026).

\section{References}

[1] Hou X., Mei J., Zuo C. Overview of urban rail transit lines in Chinese mainland in 2020. Urban Rapid Rail Transit, Vol. 34, Issue 1, 2020, p. 12-17, (in Chinese).

[2] Xia H., Wu X., Yu D. Environmental vibration induced by urban rail transit system. Journal of Northern Jiaotong University, Vol. 23, Issue 4, 1999, p. 7-13, (in Chinese).

[3] Gupta S., Liu W. F., Degrande G., Lombaert G., Liu W. N. Prediction of vibrations induced by underground railway traffic in Beijing. Journal of Sound and Vibration, Vol. 310, Issue 3, 2008, p. 608-630.

[4] Kowalska Koczwara A. Influence of location of measurement point on evaluation of human perception of vibration. Journal of Measurements in Engineering, Vol. 7, Issue 3, 2019, p. 147-154.

[5] Yuan Y., Liu W., Wang W. Experiments on environmental vibration propagation characteristics induced by metro traffic. Journal of the China Railway Society, Vol. 36, Issue 4, 2014, p. 99-104, (in Chinese).

[6] Hou J., Li S., Yuan G., Jiang W. Measurement and analysis of vibration transfer in the tunnel of Suzhou No. 1 Metro. Noise and Vibration Control, Vol. 34, Issue 5, 2014, p. 82-85, (in Chinese).

[7] He G. Vibration Reduction Effect Analysis and Influencing Factors of Damping Layer in Shenzhen Subway Tunnel. Master Thesis, Wuhan University of Technology, Wuhan, 2018, (in Chinese).

[8] Cai X., Li D., Zhang Y., Miao Q., Cui R. Experimental study on the vibration control effect of long elastic sleeper track in subways. Shock and Vibration, Vol. 2018, 2018, p. 6209518.

[9] Xu Q., Chen X., Yan B., Guo W. Study on vibration reduction slab track and adjacent transition section in high-speed railway tunnel. Journal of Vibroengineering, Vol. 17, Issue 2, 2015, p. 905-916. 